\title{
THE RELATION OF CIRCUL.ATING ANTIPNEUMOCOCCAL IMMUNE SUBSTANCES TO THE COURSE OF LOBAR PNEUMONIA
}

\section{NATURAL IMMUNE SUBSTANCES}

By O. H. ROBERTSON, JAMES B. GRAESER, LOWELL T. COGGESHALL,
AND M. AGNES HARRISON

(From the Department of Medicine and the Douglas Smith Foundation for Medical Research of the University of Chicago, Chicago)

(Received for publication March 12, 1934)

Interest in the humoral immune properties of the blood of patients with pneumococcus lobar pneumonia has centered principally on the possible relationship of acquired anti-pneumococcal activity of the serum to recovery from the disease. While much information has been collected on the subject by numerous workers, the nature of this relationship still remains problematical. Actually little has been added except corroboration to the results of Dochez's original investigation (1912) (1) in which he found that at about the time of crisis the blood serum of most patients recovering from pneumonia, in contrast to fatal cases, acquired the ability to protect mice against infection with highly virulent pneumococci. However, this immune property was not detected in every case and its appearance did not always coincide with the time of recovery. More recent studies have shown that the appearance of acquired antipneumococcal activity in the serum marks the termination of bacteremia ${ }^{1}$ but whether this manifestation of the body's reaction is of primary or secondary significance in the mechanism of recovery, the present methods of investigation have failed to reveal.

A somewhat different conception of the problem was offered us by finding that the blood serum of normal human beings, as a group, possesses well marked pneumococcidal-promoting properties as shown by the in-vitro action of human serum-leukocyte mixtures (2). ${ }^{2}$ The observation further that the serum of certain individuals lacked this property for one or more of the types of pneumococcus, while exhibiting it for the other types, suggested that there might be a relationship between the presence or absence of natural antipneumococcal humoral immunity and the inception of lobar pneumonia. A study of the serum activity of pneumonia patients, very early in the course of the disease, not only failed to disclose any such re-

1 The rarely observed exceptions to this finding will be discussed in Paper II.

${ }^{2}$ Similar observations were made at about the same time by Ward (3) and Sutliff and Rhoades (4). 
lationship, but brought out the unexpected finding that lobar pneumonia could occur in patients whose blood possessed a normal degree of pneumococcus-killing power for the homologous microorganisms (5). Since this action of the blood was significant in respect to the numbers of pneumococci destroyed by the serum and leukocytes contained in a unit of blood ${ }^{3}$ and was not infrequently found to persist throughout the course of the disease, the question as to what influence such an environment might exert on the evolution of the disease process presented itself as of prime importance. It seemed not improbable that the ultimate extent of pulmonary tissue involved and the degree of localization of the pneumococci in the lung might well be contingent on the concentration of the natural antipneumococcal forces of the blood. Such studies were undertaken and also extended to include analogous observations on the so-called acquired immune substances, and the immune properties produced in the blood by the injection of specific antipneumococcus serum. The data relative to each part of the study will be presented separately.

\section{METHODS OF STUDY}

Our observations were directed principally toward securing evidence of changes in the extent of the pulmonary lesion and the detection of bacteremia, in relation to the concentration of circulating immune substances, during the progression of the disease. The spread of the lesion was determined by daily $\mathrm{x}$-rays; for the most part flat films were made with a portable $x$-ray machine, but latterly stereoscopic films have been secured by means of a special apparatus devised by Hodges and Lipscomb (6). The physical findings were also recorded graphically each day. The details of the $x$-ray study have been described in a previous publication (7). The interpretation of the $\mathrm{x}$-ray films was made by Dr. Paul C. Hodges, to whom we are much indebted. The area of the lung field occupied by the shadow of the lesion was estimated by dividing the field into quarters. These figures are, of course, only approximate, but of significance in a comparison of the size of the pulmonary lesion from day to day. We considered this procedure much more satisfactory than attempting to determine how much of a single lobe is involved or determining the boundaries of the lobes.

Blood cultures were made in the usual way with one and two cc. of blood in dextrose blood agar plates, $\mathrm{pH} 7.6-7.8$, and five to six cc. of blood in 0.05 per cent dextrose meat infusion broth, $\mathrm{pH} 7.8$, with the addition of 2 per cent rabbit serum.

The pneumococcidal tests were carried out as described in previous publications (8) (9) (2) using human leukocytes. The several blood

3 The number of pneumococci killed by the serum and leukocytes contained in $0.5 \mathrm{cc}$. of pooled human blood ranged from 10,000 to $1,000,000$ pairs of organisms depending on the strain of pneumococcus tested. 
samples for each case were tested at one time as soon as the study was completed. However, it was found that after a week, deterioration of the immune substances began so that if the observations extended over a longer period, the samples already collected were tested at the end of six or seven days, and those subsequently secured were tested at the completion of the study, together with several of the more recent blood specimens of the earlier test. The pneumococci employed in the tests were isolated from the patient's blood, lung (by puncture) or sputum. Numerous experiments were carried out in which pneumococci obtained from two or three of the above sources were tested against a single blood sample with identical results.

Since the pneumococcidal reaction, as performed in these experiments, has been found to depend principally, if not entirely on opsonization, phagocytosis and intracellular digestion (10), and since serum possessing the power to promote such an effect also exhibits agglutinative and mouse protective activity to varying degrees, the terms immune substance and immune body in common use, will be employed interchangeably with pneumococcidal activity, keeping in mind that the former designations indicate nothing more than a specific property of the serum.

\section{CLINICAL OBSERVATIONS}

Twenty-four patients suffering from lobar pneumonia due to pneumococcus Types I, II, III and Group IV were studied in the manner just described. In addition, observations on the pneumococcidal-promoting activity of the blood and on bacteremia were made in five cases without accompanying serial $x$-rays. While this series of cases is much too limited to permit any inferences based on percentage variations, there have emerged from the data collected, certain findings which do not require statistical support for their interpretation.

\section{Spread of the pulmonary lesion}

The most significant of these findings is the absence of any detectable relationship between the concentration of natural antipneumococcal immune substances in the blood and the spread of the disease process in the lungs. A perusal of Table $I$, in which a summary of the data secured on each patient is presented, shows that spread of the lesion occurred in patients with pneumococcidal power in the blood as well as in those lacking this property. Furthermore, the persistence of the humoral immunity through the active stages of the disease had no apparent effect upon the ultimate extent of the pulmonary lesion. An instance in which marked spread of the process occurred in the presence of a normal concentration of immune substances is shown graphically in Chart I, Case 11 (N. S.). On the second day of the disease the lesion occupied a little over half of the left lung field. The process continued to spread until the 7 th day when it 
TABLE I

Relation of natural immune substances to spread of lesion, blood invasion and outcome

\begin{tabular}{|c|c|c|c|c|c|c|c|c|}
\hline \multirow{3}{*}{$\begin{array}{c}\text { Case } \\
\text { number }\end{array}$} & \multirow{3}{*}{$\begin{array}{c}\text { Pneu- } \\
\text { mococ- } \\
\text { cus } \\
\text { type }\end{array}$} & \multirow{3}{*}{$\begin{array}{c}\text { Day of } \\
\text { first ob- } \\
\text { serva- } \\
\text { tions }\end{array}$} & \multirow{2}{*}{\multicolumn{2}{|c|}{$\begin{array}{c}\text { Pneumococcidal- } \\
\text { promoting activity } \\
\text { of patient's serum }\end{array}$}} & \multirow{3}{*}{ 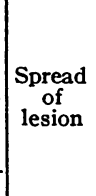 } & \multicolumn{2}{|c|}{ Blood invasion at } & \multirow{3}{*}{ Outcome } \\
\hline & & & & & & \multirow{2}{*}{$\begin{array}{c}\text { Begin- } \\
\text { ning } \\
\text { of } \\
\text { observa- } \\
\text { tions }\end{array}$} & \multirow{2}{*}{$\begin{array}{c}\text { End } \\
\text { of } \\
\text { disease }\end{array}$} & \\
\hline & & & $\begin{array}{c}\text { Initial } \\
\text { test }\end{array}$ & $\mid \begin{array}{c}\text { Increase } \\
\text { or } \\
\text { decreaset }\end{array}$ & & & & \\
\hline 1. H. C. & III & 1st & $+\left(10^{-7}\right)$ & $=$ & $\mathbf{0}$ & + & 0 & Rec'd 3d day \\
\hline 2. V. C. & III & $2 c$ & $+\left(10^{-4}\right)$ & $>0$ & + & 0 & + & day \\
\hline 3. E. D. & IIa & $3 \mathrm{~d}$ & $+\left(10^{-7}\right)$ & $>0$ & + & + & + & Died 5th day \\
\hline 4. R. M. E & IIa & $1 \mathrm{st}$ & $+\left(10^{-5}\right)$ & $>10^{-7}$ & + & 0 & 0 & Rec'd 6th day \\
\hline 5. K. H.. & III & 1st & $+\left(10^{-5}\right)$ & $=$ & + & 0 & $\mathbf{0}$ & Rec'd 6th day \\
\hline 6. N. H.. & IV & 5 th & $+\left(10^{-6}\right)$ & $>0$ & + & 0 & + & Died 12 th day \\
\hline 7. G. H. & I & $2 \mathrm{~d}$ & $+\left(10^{-5}\right)$ & $-{ }^{*}$ & + & 0 & 0 & Rec'd 4th day \\
\hline 8. A. M. & II & 1st & $+\left(10^{-6}\right)$ & $-*$ & + & 0 & 0 & th day \\
\hline 9. H.F. & IV & $2 \mathrm{~d}$ & $+\left(10^{-5}\right)$ & $>10^{-8}$ & + & 0 & + & h day \\
\hline 10. W. S.. & IV & 4 th & $+\left(10^{-5}\right)$ & $<10^{-4}$ & $t$ & + & 0 & day \\
\hline 11. N.S. & II & $2 \mathrm{~d}$ & $+\left(10^{-4}\right)$ & $=$ & + & 0 & $\mathbf{0}$ & day \\
\hline 12. K. V. & IV & $2 d$ & $+\left(10^{-6}\right)$ & $<10^{-5}$ & + & 0 & 0 & th day \\
\hline 13. A. Z & III & $3 c$ & $+\left(10^{-6}\right)$ & $=$ & + & 0 & 0 & day \\
\hline 14. F... & II a & $2 d$ & $+\left(10^{-4}\right)$ & $=$ & - & $\mathbf{0}$ & $\mathbf{0}$ & day \\
\hline 15. C. Mc & II & $3 d$ & $+\left(10^{-7}\right)$ & $>0$ & - & 0 & 0 & th day \\
\hline 16. R. E & IV & 4th & 0 & $<10^{-5}$ & $+\nabla$ & 0 & $\mathbf{0}$ & th day \\
\hline 17. B. G. & II a & $3 d$ & 0 & $=$ & 0 & 0 & $\mathbf{0}$ & day \\
\hline 18. G. Y.. & IIa & $3 d$ & $\mathbf{0}$ & $<10^{-4}$ & - & 0 & $\mathbf{0}$ & day \\
\hline 19. M. K. & IV & $2 d$ & $\mathbf{0}$ & $<10^{-4}$ & 0 & 0 & 0 & day \\
\hline 20. F. V. & IV & 4th & $\mathbf{0}$ & $<10^{-4}$ & 0 & 0 & $\mathbf{0}$ & th day \\
\hline 21. A. L. & I & 1st & $\mathbf{0}$ & $<10^{-4}$ & $+\bullet$ & 0 & $\mathbf{0}$ & th day \\
\hline 22. W. McC. & I & $3 \mathrm{~d}$ & $\mathbf{0}$ & $<10^{-4}$ &.+ & 0 & 0 & th day \\
\hline 23. L. M. B. & IIa & 4th & 0 & $=$ & 0 & + & + & Rec'd 8th day \\
\hline 24. R. M... & III & 5 th & 0 & $=$ & + & 0 & + & Died 9th day \\
\hline 25. M. R & IIa & $3 d$ & $\mathbf{0}$ & $=$ & + & 0 & 0 & 6th day \\
\hline 26. R. H. . & I & 1st & 0 & $=$ & $+^{* *}$ & 0 & 0 & Rec'd 5th day \\
\hline 27. H.F.L.V & IIa & 5 th & $\mathbf{0}$ & $=$ & - & 0 & 0 & Rec'd 6th day \\
\hline 28. J. V.... & II & $2 d$ & 0 & - & - & + & - & Died $2 \mathrm{~d}$ day \\
\hline 29. R. O. . & I & 1st & 0 & $-{ }^{*}$ & + & 0 & $\mathbf{0}$ & Rec'd 5th day \\
\hline
\end{tabular}

* Serum treatment began 24 hours later.

** Serum treatment began after 48 hours.

$\nabla$ No spread after appearance of immune substances.

$\because$ Spread in previously involved lobe only.

+ The period covered by these tests is confined to the active stage of the disease, i.e. up to, but not including the day of beginning recovery.

+ Present.

0 Absent.

- No observations made.

$<$ Increase.

$>$ Decrease.

$=$ No change.

Rec'd $=$ Recovered.

The minus powers of 10 under "Pneumococcidal-promoting activity of patient's serum" indicate quantities of the standard pneumococcus suspension killed by $0.2 \mathrm{cc}$. patient's serum and leukocytes from $0.5 \mathrm{cc}$. of normal human blood containing 10,000 W.B.C. per c.mm. The standard pneumococcus suspension contains 1 billion pairs of pneumococci per cc. Thus $10^{-7}$ equals approximately 100 pneumococci, $10^{-6}, 1000 ; 10^{-5}, 10,000$, etc. 
was estimated that more than three quarters of the entire lung area was involved. During all this period daily tests of the pneumococcidal-promoting activity of the patients' serum revealed the presence of this property to a normal degree. On the 8th day of the disease a decided drop in the titer of immune substances occurred coincident with beginning resolution, but

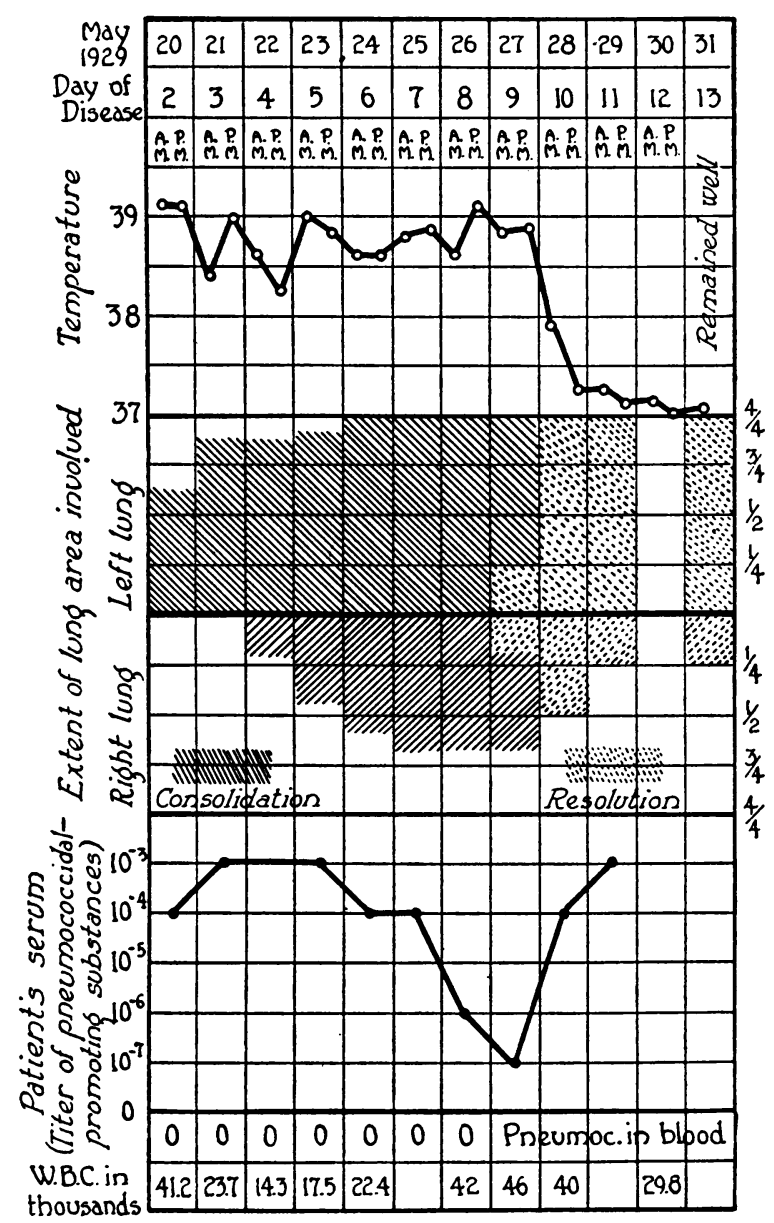

Chart I. Case Number 11 (N. S.). Lobar Pneumonia, Pneumococcus Type II Isolated from the SPUtum

the concentration increased rapidly again as recovery progressed. In contrast to this patient, four cases, Numbers 17, 19, 20 and 23 (Tables I and II) showed no demonstrable humoral immunity and no spread of the lesion during the period of observation.

Of equal, but perhaps of somewhat different significance, is the course of the disease exhibited in Chart II. The lesion in this patient (Number 
TABLE II

Case 20 (F. V.) Hospital number 11423. Lobar consolidation of right lower lobe. Pneumococcus Group IV isolated from lung and blood

\begin{tabular}{|c|c|c|c|c|c|c|c|c|}
\hline $\begin{array}{l}\text { Date. } \\
\text { Day of disease....................... }\end{array}$ & $\begin{array}{r}24 \\
4\end{array}$ & $\begin{array}{r}25 \\
5\end{array}$ & $\begin{array}{r}26 \\
6\end{array}$ & $\begin{array}{r}27 \\
7\end{array}$ & $\begin{array}{r}28 \\
8\end{array}$ & $\begin{array}{r}29 \\
9\end{array}$ & $\begin{array}{l}30 \\
10\end{array}$ & $\underset{11}{\text { May } 1}$ \\
\hline \multicolumn{9}{|l|}{$\begin{array}{l}\text { Pneumococcidal - promoting } \\
\text { action of patient's serum }\end{array}$} \\
\hline Fresh whole serum. . . . . . & $\mathbf{0}$ & $\mathbf{0}$ & $10^{-7}$ & $\mathbf{0}$ & $10^{-4}$ & $10^{-4}$ & $10^{-3}$ & $10^{-3}$ \\
\hline & - & - & - & - & $\mathbf{0}$ & $\mathbf{0}$ & 0 & 0 \\
\hline Blood cultures............ & 0 & $\mathbf{0}$ & $+^{*}$ & $\mathbf{0}$ & $\mathbf{0}$ & $\mathbf{0}$ & & \\
\hline \multirow{2}{*}{\multicolumn{9}{|c|}{$\begin{array}{l}\text { Evolution of lesion } \dagger \\
\quad \mathrm{X} \text {-ray } \ldots . . . \ldots \ldots \ldots\end{array}$}} \\
\hline & & & & & & & & \\
\hline \multirow{2}{*}{\multicolumn{9}{|c|}{$\begin{array}{l}\text { Physical signs............... } \\
\text { Termination of disease. } \ldots \ldots\end{array}$}} \\
\hline & & & & & & & ysis.. & \\
\hline White blood cells in thousands & 4.0 & 6.0 & 7.5 & 8.8 & 19.0 & 24.5 & 14.0 & 13.0 \\
\hline
\end{tabular}

$+\mathrm{R} 2 / 3$ signifies an $\mathrm{x}$-ray shadow occupying $2 / 3$ of the right lung field.

$=$ indicates no change in the size or character of the $x$-ray shadow.

$>$ indicates beginning clearing of the lesion.

* 8 colonies.

$12 \mathrm{~K}$. V.) showed a progressive spread into a new lobe at a time when resolution was occurring in the initially involved area. A fair degree of humoral immunity was present in the serum during this period.

\section{BACTEREMIA}

Our earlier studies on human cases of lobar pneumonia and experimentally infected animals suggested that there was a definite relationship between the presence of natural pneumococcidal-promoting properties in the blood and bacteremia. The present data make it necessary to qualify this inference to a considerable degree. In the present series of cases the occurrence of bacteremia was no more frequent in the patients lacking detectable humoral immunity than it was in those showing such serum activity. However, invasion of the blood stream was not found in those patients in whom the concentration of immune substances remained within normal limits. One exception to this finding was shown by Case 10 (W. S.) whose blood on one occasion yielded growth in the broth flask without growth on the plate and at the same time was found to possess a pneumococcidal-promoting power of $10^{-5}$ (10,000 pneumococci killed). Furthermore, a marked diminution or disappearance of humoral immunity during the course of the disease was usually followed by bacteremia. But exceptions to this finding were observed. Case 15, in whom the pneumococcidal-promoting properties of the blood had disappeared, showed a sterile blood 12 hours before death. Invasion of the blood stream was also noted 


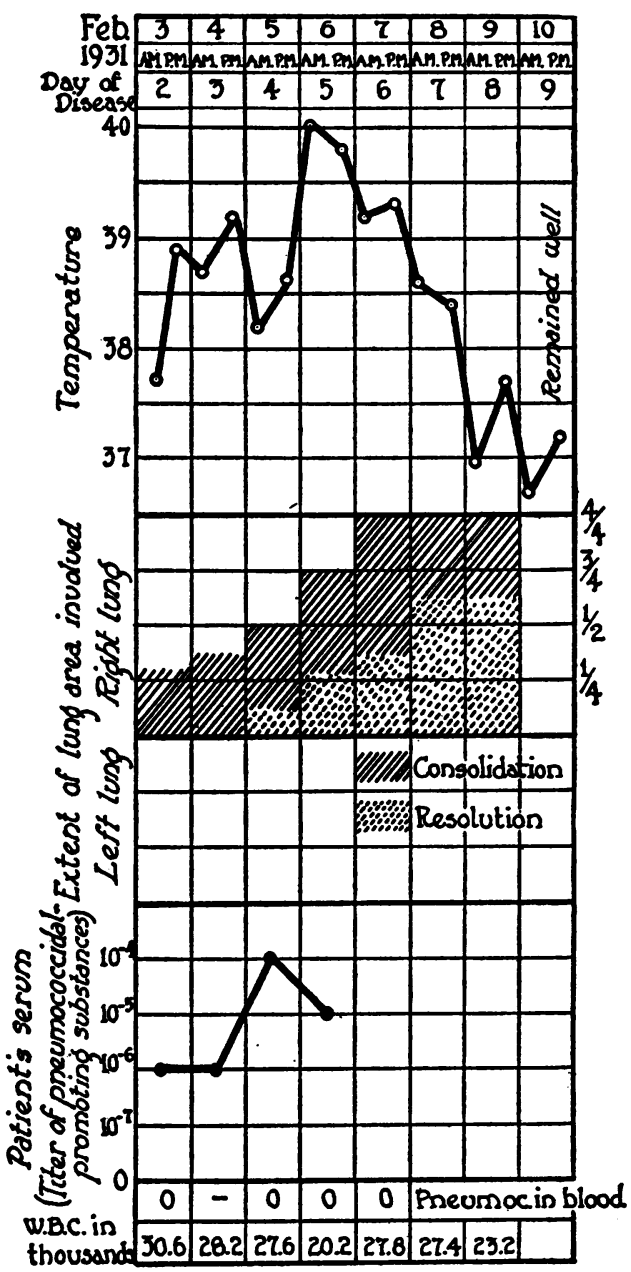

Chart II. Case Number 12 (K. V.). Lobar Pneumonia, Pneumococcus Group IV Isolated from the SPUTUM

in two cases exhibiting a minimal concentration of immune substances. (Cases 1 and 9.)

\section{Outcome of disease}

Since the occurrence of pneumococcidal-promoting activity in the serum was found to bear no relationship to the inception of the disease (5), the spread of the pulmonary lesion or the invasion of the blood stream, one would hardly expect that any prognostic value as to outcome could be attached to presence or absence of this property in the blood. Our data show such to be the case. Patients exhibiting an initial absence of humoral immunity were just as likely to recover as those possessing it to a normal 
degree. However, in all the fatal cases, with one exception (Case 9), the serum was found to be without immune activity at the end of the disease, whether or not it had been present earlier.

There were no significant differences in the number of circulating leukocytes between the patients with and without demonstrable humoral immune properties.

It will be noted in Table I that in a number of cases showing no serum pneumococcidal-promoting activity in the initial tests, this property appeared toward the end of the disease. Does this represent a reappearance of the natural immune substances or does it indicate newly acquired immunity? Since the data bearing on this question are presented in the next section, a discussion of the subject will be deferred until that time. Suffice it to say here that the evidence available points to the latter explanation.

\section{DISCUSSION}

In view of the observations just described, what conclusions are to be drawn concerning the relationship of natural immune substances to the course of lobar pneumonia? The one apparent effect of the persistence of a normal degree of pneumococcidal-promoting power of the serum, namely the maintenance of a sterile blood, was not without exception. The observations of Sutliff and Rhoades (11) indicate that bacteremia in the presence of well marked pneumococcidal activity of the blood is not of uncommon occurrence. While these authors made no attempt to differentiate between natural and acquired immune substances, their finding of pneumococcus-killing power in the blood, early in the course of lobar pneumonia, makes it highly probable that in such instances they were dealing with natural serum immunity.

In a discussion of the differences observed among the various animal species, including man, in respect to their ability to localize pneumococcus infection, Trask, O'Donovan, Moore and Beebe (12) present a diagram showing a curve dropping at the top from man through the child, immunized monkey, normal monkey, immunized rabbit down to normal rabbit at the bottom on an ordinate of the diminishing typical clinical picture of lobar pneumonia. The base line represents increasing pneumococcemia, most marked in the rabbit. Would it be possible to express pneumococcus susceptibility of other animal species in such manner? While adequate data is lacking in most instances, our recent production of experimental lobar pneumonia in the dog provides another instance of an animal with a resistance against the pneumococcus analogous to that of adult man and showing the ability to localize the infection in the lungs with the production of a lesion similar, in general, to clinical lobar pneumonia (13). We also found that the natural antipneumococcal immune substances, present in the dogs blood, often persisted in considerable concentration throughout the course of the experimental disease. Their disappearance was usually fol- 
lowed by bacteremia and only rarely did blood invasion occur in the presence of humoral immunity. Just as was observed in human beings, extension of the lesion in the experimental pneumonia occurred whether or not immune substances were detectable in the blood.

Our present knowledge does not permit us to infer more than that those animal species possessing circulating immune bodies are endowed with the capacity to localize pneumococcus infection. Individuals of the species may lack such demonstrable immunity, but nevertheless be competent to localize the infective process. Tests on the common laboratory animals exhibiting a high degree of resistance to the pneumococcus including horse, sheep, dog, cat and pig, have shown them to possess natural antipneumococcal immune substances $(10) .^{*}$ Whether these animals are all capable of localizing pneumococci in the lungs to produce the clinical picture of lobar pneumonia we do not know. However, lobar pneumonia does occur spontaneously in horses and we have produced in the cat (in a few instances) lobar pneumonia which appears to resemble the experimental disease in the dog. In the absence of complete experimental data, we are furthermore unable to draw any general conclusions concerning those animals which do not possess natural demonstrable circulating immune substances. The animals recognized as belonging to this group, the guinea pig and the rabbit, show very little ability to localize pneumococcus infection, but whether all animal species capable of localizing this microorganism show humoral immunity is not known. While tests for pneumococcidal activity in the blood of normal monkeys have not been reported, certain studies on the mouse protective properties of their serum suggest that demonstrable natural humoral immunity is either very slight or absent though lobar pneumonia can be produced readily in this species.

Thus quite apart from such possible species variations as may be presented by the monkey, the finding of individuals within a pneumococcus resistant group (exemplified by man) who do not possess demonstrable antipneumococcal immune substances, leaves no other alternative than to assume the existence of other unknown factors in the mechanism of natural resistance to the pneumococcus.

\section{SUM MARY}

A study of twenty-nine cases of pneumococcus lobar pneumonia was made with a view to determining the possible relationship of circulating natural antipneumococcal immune substances to the spread of the pneu-

4 In this study (10) human beings were classified erroneously as a susceptible animal. The cause of this error became apparent in later investigations in which it was found that there exists in normal human beings great variations in the concentration of natural immune substances in the blood. The several individuals tested in the earlier study showed an absence of antipneumococcal activity of the serum for the Type I Pneumococcus used. 
monic lesion, the localization of the infection in the lung and the outcome of the disease. The immune properties of the blood were determined by testing the pneumococcidal-promoting action of the serum. Data on changes in the extent and character of the pulmonary process were secured principally from daily $\mathrm{x}$-rays of the chest.

No relationship was found between the presence or absence of detectable humoral immunity and the extension of the lesion. Active spread of the process from lobe to lobe occurred in certain patients showing the persistence of a normal pneumococcidal-promoting power in the blood. In other cases in which the serum lacked this property the lesion showed no increase in size throughout the period of observation. Likewise the initial concentration of immune substances in the blood had no observable significance in relation to the outcome of the disease. Patients without detectable humoral immunity were just as likely to recover as those showing this property to a normal degree. In respect to the frequency of bacteremia, however, there was a difference between these two types of patients. With only one exception, the blood of those cases showing the persistence of a normal degree of pneumococcidal-promoting power, remained sterile, while bacteremia was of relatively frequent occurrence in patients lacking this property, initially or losing it during the course of the disease. On the other hand a number of patients without demonstrable serum immunity showed a persistent absence of blood invasion. We are thus left with the conclusion that the natural circulating antipneumococcal immune substances play at most a very minor rôle in the course of lobar pneumonia.

\section{BIBLIOGRAPHY}

1. Dochez, A. R., The presence of protective substances in human serum during lobar pneumonia. J. Exper. Med., 1912, 16, 665.

2. Robertson, O. H., and Cornwell, M. Agnes, A study of the resistance of normal human beings to recently isolated strains of pathogenic pneumococci. J. Exper. Med., 1930, 52, 267.

3. Ward, H. K., Observations on the phagocytosis of the pneumococcus by human whole blood. I. The normal phagocytic titre and the antiphagocytic effect of the specific soluble substance. J. Exper. Med., 1930, 51, 675.

4. Sutliff, W. D., and Rhoades, D. R., The pneumococcidal power of whole blood. I. Description of method. Result in individuals with no history of lobar pneumonia. J. Clin. Invest., 1930, 9, 43.

5. Robertson, O. H., Terrell, E. E., Graeser, J. B., and Cornwell, M. Agnes, The relation of natural humoral antipneumococcal immunity to the inception of lobar pneumonia. J. Exper. Med., 1930, 52, 421.

6. Hodges, P. C., and Lipscomb, T., Stereoscopic roentgenography of bedridden pneumonia patients. (To be published in the J. Lab. and Clin. Med.)

7. Graeser, J. B., Wu, C., and Robertson, O. H., Physical signs and roentgenographic findings in lobar pneumonia in adults. Arch. Int. Med., 1934, 53, 249. 
8. Robertson, O. H., and Sia, R. H. P., Studies on pneumococcus growth inhibition. II. A method for demonstrating the growth-inhibitory and bactericidal action of normal serum-leucocyte mixtures. J. Exper. Med., 1924, 39, 219.

9. Robertson, O. H., Woo, S. T., and Cheer, S. N., Studies on pneumococcus growth inhibition. IV. A simplified agitator for growth inhibition tests with serum-leucocyte mixtures; and certain modifications in the technique of the test. J. Exper. Med., 1924, 40, 487.

10. Robertson, O. H., and Sia, R. H. P., Studies on pneumococcus growth inhibition. VII. The relation of opsonins to natural resistance against pneumococcus infection. J. Exper. Med., 1927, 46, 239.

11. Sutliff, W. D., and Rhoades, D. R., The pneumococcidal power of whole blood. II. Estimations in lobar pneumonia. J. Clin. Invest., 1930, 9, 55.

12. Trask, J. D., O'Donovan, C., Jr., Moore, D. M., and Beebe, A. R., Studies on pneumonia in children. I. Mortality, blood cultures, and humoral antibodies in pneumococcus pneumonia. J. Clin. Invest., 1930, 8, 623.

13. Terrell, E. E., Robertson, O. H., and Coggeshall, L. T., Experimental pneumococcus lobar pneumonia in the dog. I. Method of production and course of the disease. J. Clin. Invest., 1933, 12, 393. 